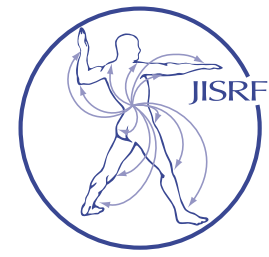

\title{
Native Patella Retention Versus Resurfacing in a Cohort of Staged Bilateral Total Knee Patients
}

\author{
Head $J^{1}$, Nelson $R^{1}$, Dyball $M^{1}$, Lawrence $B^{1}$
}

\begin{abstract}
Background: Patellar resurfacing in total knee arthroplasty remains a point of controversy within the literature and the generally followed paradigm varies among regions.

Methods: In effort to elucidate a difference following the change from universal patellar resurfacing to universal non-resurfacing, 32 patients with bilateral TKA that included one resurfaced and one native patella were retrospectively reviewed at average follow up 21.4 months from the most recent surgery.

Results: No difference was observed in patient satisfaction, KOOS-ADL score, and VAS scores. No complications or secondary patellar resurfacing occurred.

Conclusions: Therefore, patients perceive no difference between knees with native patella retention or a resurfaced patella in regards to pain and function.
\end{abstract}

\section{Background}

The first total knee arthroplasty (TKA) prosthesis designs essentially ignored the patellofemoral joint, as the tibia-femoral replacements were seen as an alternative to arthrodesis for severe axial deformities, with success gauged as any improvement in function and pain relief. $[1,2]$ Subsequent prosthesis designs evolved to account for the increased reports of patellofemoral complications with specific implant designs for the patella, which became universally accepted as an integral part of TKA, providing an improved level of patient satisfaction. [그-6 $]$

However, with new designs came new complications, which included: patellar fracture, disruption of the extensor mechanism, osteonecrosis, aseptic loosening, instability and dislocation, "overstuffing" of the patellofemoral joint, catastrophic failure, patellar polyethylene wear, and patellar clunk syndrome. [ $\underline{3}, \underline{7-11]}$ This gave rise to the re-thinking whether or not to resurface the native patella. While some studies and meta-analysis have shown patella resurfacing to be better in terms of cost-effectiveness, reduced revision rate for anterior knee pain, and produced less anterior knee pain, emerging evidence suggests that resurfacing has no influence on the clinical outcome of the patient. [12-17] Proponents of retention of the native patella claim that it has no affect on total healthcare cost, reoperation rate or functional outcome and has a lower complication rate. [18-21]

TKA is one of the most commonly performed operations in adult reconstructive surgery and there currently exists three different approaches among orthopedic surgeons regarding patellar resurfacing: resurfacing all patellae, not resurfacing all patellae, and selective resurfacing for patients with significant pre-operative patellofemoral arthritis-related symptoms and/or advanced patellofemoral arthritis on radiographs. Certain advantages and possible

\footnotetext{
Keywords: Total knee arthroplasty, patella resurfacing, native patella, bilateral total knee, anterior knee pain, patella retention Level of Evidence: AAOS Therapeutic Level III

Educational Value \& Significance: JISRF Level A
} 
complications reported in the literature can guide the surgeon toward establishing a practice paradigm.

In the present study, we aimed to retrospectively assess whether a difference exists in the function and pain relief after total knee arthroplasty in knees treated with patella resurfacing and knees with native patellae. Our patient population consisted of consecutively performed, staged bilateral TKA in which the first patella was resurfaced and the subsequent patella was left unresurfaced. Our hypothesis, was that there would be no measurable difference from the resurfacing side to the native side.

\section{Methods}

The two senior authors changed their practice from always resurfacing the patella up to 2012 to never resurfacing the patella, thereafter. Following this paradigm shift, the implant was not changed, nor any other part of the operative technique.

\section{Patient population}

We retrospectively reviewed patient records for consecutively performed, staged bilateral TKA in which the first patella was resurfaced and the subsequent patella was left unresurfaced. Our aim was to collect their Knee injury and Osteoarthritis Outcome Score for Activities of Daily Living (KOOS-ADL), VAS, and satisfaction of both knees and determine if there was a difference between resurfaced versus unresurfaced patella, within the same patient. After hospital Institutional Review Board approval was obtained, informed consent for record review and survey administration was obtained from all patients prior to voluntary participation in the study.

Included patients had minimum 12 months follow up and were recruited from 2007 to 2015. Of the available 34 patients, two were lost to follow up, leaving 32 patients participants in the study. Patients were contacted via phone and a single clinician administered a survey consisting of The Knee injury and Osteoarthritis Outcome Score for Activities of Daily Living (KOOS-ADL), visual analog score, and patient satisfaction. The survey administrator was blinded to all patient information and surgical records. Data from the above outcome measures were analyzed with Student's t-test.

\section{Operative Technique}

The surgical procedure was performed under spinal anesthesia or utilizing general anesthesia, when requested by the patient or indicated per the treating anesthesiologist. No peripheral nerve blocks were used. We employed a midline incision and a medial parapatellar arthrotomy. The patella was everted and the patellofemoral joint was inspected. During procedures performed prior to 2012, patellae were universally resurfaced and, after a paradigm shift in clinical practice in 2012, the two senior authors began leaving all patellae unresurfaced.

The DePuy Sigma fixed bearing cruciate-retaining knee system was utilized in all cases. The femoral component was externally rotated three degrees from the posterior condylar axis and implants were fixed with standard cementing technique.

Patellar osteophytes were excised and neurectomy performed in all cases. When the patella was resurfaced the composite patellar thickness was restored to within $2 \mathrm{~mm}$ of the pre-resection thickness. The patellar component was an all polyethylene dome-shaped implant with three fixation pegs and the patellar surface was prepared with standard cementing technique. A lateral retinacular release was performed when the patella was not centered in the trochlea with the knee flexed $45^{\circ}$ and the medial capsular retinaculum approximated.

\section{Results}

The retrospective review gave us 32 patients with a mean age 68.4 (range 47-84) and BMI of 32.8 (range 25.746.1). The mean duration of follow up was 21.4 months (range 12-46) for the unresurfaced group and 51.3 months (range 16-97) for the resurfaced group. There were no intraoperative complications. One patient in the resurfaced group and two patients in the un resurface group had lateral release performed at time of index procedure. There were no revisions on resurfaced or native patella sides.

A Student's t-test demonstrated no significant difference in the KOOS-ADL at time the of the interview with the mean in the resurfaced group $88.0+-7.37$ (95\% CI 85.4 to 90.6$)$ and $89.1+-7.17$ (95\% CI 86.6 to 91.6$)$ in the unresurfaced group $(\mathrm{p}=0.914)$. The questions were then analyzed for seven questions specifically pertaining to patellofemoral symptoms which showed no statistical significance on Student's t-test ( $\mathrm{p}=0.975)$ (Table 1). There was also no significant difference in the VAS with a mean in the resurfaced group of $1.7+-1.37$ and 1.9+- 1.51 in the unresurfaced group $(\mathrm{p}=0.667)$. With regard to the patient satisfaction, again no significant difference was noted with a mean satisfaction in the resurfaced group of $9.4+-1.21$ and 9.4+- 1.04 in the unresurfaced group $(\mathrm{p}=1)$. 
Table 1. Patellofemoral-specific KOOS-ADL scores for the cohort.

\begin{tabular}{|l|c|c|}
\hline & \multicolumn{2}{|c|}{ Mean \pm SD KOOS-ADL score, points } \\
\hline Parameter & $\begin{array}{c}\text { Resurfaced } \\
\text { Patella }\end{array}$ & $\begin{array}{c}\text { Unresurfaced } \\
\text { Patella }\end{array}$ \\
\hline Grinding or grating & $4.88 \pm 0.4$ & $4.91 \pm 0.5$ \\
\hline Stair climbing & $4.42 \pm 0.8$ & $4.51 \pm 0.6$ \\
\hline Stair descent & $4.15 \pm 0.3$ & $4.18 \pm 0.4$ \\
\hline Kneeling & $1.33 \pm 0.5$ & $1.33 \pm 0.7$ \\
\hline Squating & $3.51 \pm 1.0$ & $3.57 \pm 1.2$ \\
\hline Sitting with knee bent & $4.90 \pm 0.3$ & $4.87 \pm 0.5$ \\
\hline Up from chair & $4.75 \pm 0.5$ & $4.75 \pm 0.7$ \\
\hline
\end{tabular}

KOOS-ADL; The Knee injury and Osteoarthritis Outcome Score for Activities of Daily Living

\section{Discussion}

In current clinical practice a dichotomy exists regarding patellar resurfacing, owing in part to regional differences within the literature. Data from a 2009 Norway arthroplasty registry showed $2.4 \%$ of patients received a patellar component, while this number was $80 \%$ in a Danish Knee Arthroplasty Registry and over $90 \%$ in North American registries. [2,22] Literature supporting both clinical practices is immense and varies even within each country with the surgeon choice to resurface owing ultimately to a combination of education, clinical evidence, specific implant design, and cultural influence. Emerging data and meta analysis suggests maintaining the native patella in TKA has no influence on clinical outcome measures or patient satisfaction. $[17,23]$ This was the motivation for the senior authors' change from universal resurfacing to universal non-resurfacing.

The current study saw no revisions for secondary resurfacing, for patellar button related issues, or for any other reason. Patient satisfaction was equivalent between resurfaced and unresurfaced patellae $(\mathrm{p}=1)$. Further, only 4 patients rated their satisfaction with either knee under an 8 on a scale of 10 ( 2 resurfaced, 2 unresurfaced), for a dissatisfied rate of $6.2 \%$. Utilizing the Swedish Knee Register, Robertson reviewed 27,372 patients outcomes. [24] Resurfaced patella reported a $15 \%$ dissatisfaction rate compared to $19 \%$ of unresurfaced patella. Although this significant difference appears to highlight the disparity among paradigms, the resurfaced group became less satisfied with their knee over time, while the unresurfaced group remained unchanged. Considering the current revision rate for causes attributable to the resurfaced patella is approximately $12 \%$ and secondary patella resurfacing is performed in $13 \%$ of cases, the benefit of the patellar button is time dependent and the need for revision for secondary resurfacing may be balanced by the need for revision due to failed patellar components. [2] Further, revisions in unresurfaced patellae may be artificially increased as secondary resurfacing provides the only viable surgical option for this group of patients. [17]

While we found no difference in VAS scores between resurfaced and unresurfaced sides, numerous reports exist in the literature of a higher revision rate for TKA with unresurfaced patella related to anterior knee pain (AKP). $[\underline{18}, \underline{25}]$ In a prospective, randomized study of 514 consecutive primary press-fit condylar total knee replacements, Waters and Bentley found an increased prevalence of anterior knee pain in the unresurfaced patellae cohort, $25.1 \%$, compared to $3.5 \%$ in the resurfaced group. [26] Of note, 35 patients in their cohort had simultaneous bilateral TKA with one resurfaced and one unresurfaced patella. Subjectively, patients preferred the resurfaced side. However, in a small series, patients with well-tracking patella whom undergo secondary resurfacing for anterior knee pain have poor results, with only $30.7 \%$ improvement. The authors recommend appropriate patient counseling and conclude that revision for anterior knee pain in unresurfaced patella is not recommended. [27] Barrack et al reported on patients whom elect for secondary resurfacing, any perceived improvement is accompanied by recurrence of symptoms in 55\% of patients. [28] Appropriate consideration of physiotherapy for anterior knee pain may help elucidate the etiology of anterior knee pain and guide the decision for revision if patient anatomy is a cause of the anterior knee pain.

We specifically isolated KOS questions related to patellofemoral pain and function. While there was no statistical difference between resurfaced and unresurfaced knees $(\mathrm{p}=0.975)$, there was a universal lower score regarding $\mathrm{pa}-$ tients' ability to tolerate kneeling on their TKA, with no difference from resurfaced versus native patella $(\mathrm{p}=1.0)$. These results mirror the results reported in a meta-analysis of 7,075 TKA's, no difference existed regarding the incidence of AKP between resurfacing and unresurfaced group. [17]

Several reports in the literature report bilateral TKA with resurfaced and unresurfaced patella. In a prospective study, Kwon reports on 17 patients with bilateral TKA in which the patella was resurfaced on one side. After a mean follow-up of 10.6 years, no difference was observed in HSS knee scores, radiological parameters including tibiofemoral angle, width of patella, length of patella, thickness of patella, tilt of patella and shift of patella. [29] Keblish et al. prospectively followed 30 patients and reported equal outcomes for modified Hospital for Special Surgery score for all categories, including: pain, range of motion, func- 
tion, deformity, and strength. The authors concluded that with the appropriate prosthesis design and appropriate surgical technique, that retention of the patella is an acceptable option. [30] Burnett, et al. found no differences with regard to range of motion, Knee Society Clinical Rating Score, satisfaction, revision rate, or anterior knee pain in their single-stage bilateral TKA cohort of 32 patients. [31]

The influence of femoral and tibial component position on clinical outcomes warrants mention, as it may account for anterior knee pain unrelated to patellar resurfacing. It is well known that malrotation of TKA components adversely affects patella tracking and may contribute to increased patellofemoral contact pressures, thus predisposing a patient to anterior knee pain possibly leading to revision surgery. [ $\underline{32}-\underline{34}]$ One study showed a 30\% incidence of AKP when implants were placed at a combined internal rotation of 3-17 degrees compared to external rotation of 0-10 degrees. [23] Therefore, patient reported AKP must be analyzed within the entire clinical picture and not just with regards to presence or absence of patellar resurfacing.

In regards to our specific implant, Roberts, et al. also used the Depuy Sigma prosthesis and reported on a cohort of 315 selectively resurfaced patellae at 2 years minimum mean follow up. While no difference was observed in KSS scores, patient reported satisfaction was statistically higher for resurfaced patellae. The authors concluded that the clinical significance of this outcome may be minimal. [25] Liu, et al found similar results in their 133 patients randomized to receive either resurfacing with the modified dome implant or patellar reshaping; which included: resecting the partial lateral facet of the patella and the osteophytes surrounding the patella, trimming the patella to match the trochlea of the femoral component. They found no significant difference between the groups with regard to the Knee Society Scores, presence of anterior knee pain rate and radiographic differences. [35]

The present study had several strengths. The most notable being that the patient essentially acted as their own control, having one patella resurfaced and the other being left unresurfaced, which eliminated the possibility of cohort selection bias. Further, the style of patient self-reporting utilized in the KOOS-ADL survey allows for a clear delineation of a patients' preference from one knee versus the other and lends toward a definite consensus that our patient population truly had no preference between resurfaced or native patella. High patient retention and blinded survey administration by a single clinician also strengthen the study.

The main limitation of our study was that it was underpowered, which reduces the strength of our conclusion (power $=0.008)$. A larger sample size is desirable, but is precluded by the small population of patients in our practice that meet the indications. Further, an analysis of pre-operative patellofemoral symptoms and outcome differences in patients with advanced patellofemoral arthritis with resurfacing versus non-resurfacing would possibly delineate a role for selective resurfacing in this population of patients. Other limitations include the retrospective nature of the study and lack of pre-operative KOOS-ADL and VAS scores. For the observed difference in KOOS-ADL scores of 1 percentage point, the study was under powered to claim whether this minor difference was not statistically significant. However, the high satisfaction ratings and KOOS-ADL scores among both treatment groups suggest, if not equivocal, satisfaction that is acceptable regardless of the type of intervention. While this study was not sufficiently powered to prove non-inferiority for the surgeon, it is patient-based evidence suggesting that satisfaction with either resurface type may be similarly acceptable to patients. The choice to resurface is up to the surgeon, but our data provides patient-based evidence for the surgeon to discuss with his patient's when faced with questions regarding patella resurfacing.

To conclude, TKA technique may include patellar resurfacing or native patella retention without any demonstrable difference in patients' activity of daily living, overall pain, or satisfaction.

\section{References:}

1. Walldius B. Arthroplasty of the knee joint using endoprosthesis. Acta Orthop Scand Suppl 1957;24:1-112.

2. Schindler OS. The controversy of patellar resurfacing in total knee arthroplasty: Ibisne in medio tutissimus? Knee Surg Sports Traumatol Arthrosc 2013;20:122744.

3. Mochizuki RM, Schurman DJ. Patella complications following total knee arthroplasty. J Bone Jt Surg 1979;61A:879-83.

4. Insall JN, Lachiewicz PF, Burstein AH. The posterior stabilised prosthesis. A modification of the total condylar design. A two to four year clinical experience. J Bone Jt Surg 1982; 64A:1317-23.

5. Groeneveld HB.Total arthroplasty of the knee joint and the need for replacement of the patella. In: The medical engineering working party: total knee replacement. Mechanical Engineering Publications Limited, London, 1975 p.50-51.

6. Insall JN, Ranawat CS, Aglietti P, et al. A comparison of four models of total kneereplacement prostheses. J Bone Joint Surg Am 1976;58(6):754.

7. Clayton ML, Thirupathi R. Patellar complications after total condylar arthroplasty. Clin Orthop. 1982;170:152-5.

8. Aglietti P, Buzzi R, Gaudenzi A. Patellofemoral functional results and complications with the posterior stabilized total condylar knee prosthesis. J Arthroplasty 1988:3:17-25

9. Goldberg VM, Figgie HE 3rd, Inglis AE, Figgie MP, Sobel M, Kelly M, Kraay M. Patellar fracture type and prognosis in condylar total knee arthroplasty. Clin Orthop 1988;236:115-22.

10. Lombardi AV Jr, Engh GA, Volz RG, Albrigo JL, Brainard BJ. Fracture/dissociation of the polyethylene in metal-backed patellar components in total knee arthroplasty. J Bone Joint Surg Am. 1988;70:675-9.

11. Lynch AF, Rorabeck CH, Bourne RB. Extensor mechanism complications following total knee arthroplasty. J Arthroplasty. 1987;2:135-40.

12. Helmy N, Anglin C, Greidanus NV, Masri BA. To resurface or not to resurface the patella in total knee arthroplasty. Clin Orthop Relat Res 2008; 466 (11): 2775-83.

13. Clements WJ, Miller L, Whitehouse SL, Graves SE, Ryan P, Crawford RW. Early outcomes of patella resurfacing in total knee arthroplasty. Acta Orthop 2010; 81 (1): $108-13$ 
14. Murray DW, MacLennan GS, Breeman S, Dakin HA, Johnston L, Campbell MK, et al. A randomised controlled trial of the clinical effectiveness and cost-effectiveness of different knee prostheses: the Knee Arthroplasty Trial (KAT). Health Tech Ass 2014;18(19):1-235.

15. Chen K, Li G, Fu D, Yuan C, Zhang Q, Cai Z. Patellar resurfacing versus nonresurfacing in total knee arthroplasty: a meta-analysis of randomised controlled trials. Int Orthop 2013; 37 (6): 1075-83.

16. Pavlou G, Meyer C, Leonidou A, As-Sultany M, West R, Tsiridis E. Patellar resurfacing in total knee arthroplasty: does design matter? A meta-analysis of 7075 cases. J Bone Joint Surg Am 2011; 93 (14): 1301-9.

17. Pavlou G, Meyer C, Leonidou A, As-Sultany M, West R, Tsiridis E. Patellar resurfacing in total knee arthroplasty: does design matter? A meta-analysis of 7,075 cases. J Bone Jt Surg 2011;93-A:1301-1309.

18. Burnett RS, Boone JL, Rosenzweig SD, Steger-May K, Barrack R L. Patellar resurfacing compared with nonresurfacing in total knee arthroplasty. A concise follow-up of a randomized trial. J Bone Joint Surg Am 2009; 91(11):2562-7.

19. Breeman S, Campbell M, Dakin H, Fiddian N, Fitzpatrick R, Grant A, et al. Patellar resurfacing in total knee replacement: five-year clinical and economic results of a large randomized controlled trial. J Bone Joint Surg Am 2011;93(16):1473-81.

20. Group KATT, Johnston L, MacLennan G, McCormack K, Ramsay C, Walker A. The Knee Arthroplasty Trial (KAT) design features, baseline characteristics, and two-year functional outcomes after alternative approaches to knee replacement. J Bone Joint Surg Am 2009; 91 (1): 134-41.

21. Ogon M, Hartig F, Bach C, Nogler M, Steingruber I, Biedermann R. Patella resurfacing: no benefit for the long-term outcome of total knee arthroplasty. A 10- to 16.3-year follow-up. Arch Orthop Trauma Surg 2002;122(4):229-34.

22. Abdel MP. Parratte S, and Budhiparama NC. The Patella in Total Knee Arthroplasty: To Resurface or Not Is the Question. Current Reviews in Musculoskeletal Medicine 2014;7.2: 117-24.

23. Figgie HE III, Goldberg VM, Heiple KG, Moller HS III, Gordon NH. The influence of tibial-patellofemoral location on function of the knee in patients with the posterior stabilized condylar knee prosthesis. J Bone Jt Surg 1986;68:1035-40.

24. Robertsson O, Dunbar M, Phersson T, Knutson K, Lidgren L (2000) Patient satisfaction after knee arthroplasty: a report on 27,372 knees operated on between 1981 and 1995 in Sweden. Acta Orthop Scand 2000;71:262-7.

25. Roberts DW, Hayes TD, Tate CT, Lesko JP. Selective Patellar Resurfacing in Total Knee Arthroplasty: A Prospective, Randomized, Double-Blind Study. J Arthroplasty 2015;30:216-22.

26. Waters TS, Bentley G. Patellar Resurfacing in Total Knee Arthroplasty. J Bone Joint Surg. Am. 2003;85(2) 212-17.

27. Mockford BJ, Beverland DE. Secondary resurfacing of the patella in mobile-bearing total knee arthroplasty. J Arthroplasty 2005;20:898-902.

28. Barrack RL, Bertot AJ, Wolfe MW, Waldman DA, Milicic M, Myers L. Patellar resurfacing in total knee arthroplasty: A prospective randomised double blinded study with five to seven years of follow-up. J Bone Jt Surg 2001;83-A:1376-81.

29. Kwon OS, Bae DK. Comparative Analysis of Resurfaced and Unresurfaced Patella in Bilateral Total Knee Arthroplasty. J of Korean Northrop Assoc. 2003;38:478483
30. Keblish PA, Varma AK, Greenwald AS. Patellar resurfacing or retention in total knee arthroplasty. A prospective study of patients with bilateral replacements. Bone \& Joint Journal 1994;76-B(6)930-93

31. Burnett RS, Boone JL, McCarthy KP, Rosenzweig SD, Barrack RL. A prospective randomised clinical trial of patellar resurfacing and nonresurfacing in bilateral TKA. Clin Orthop Relat Res 2007;464:65-72.

32. Berger RA, Crossett LS, Jacobs JJ, Rubash HE. Malrotation causing patellofemoral complications after total knee arthroplasty. Clin Orthop Relat Res 1998;356:144-53.

33. Incavo SJ, Wild JJ, Coughlin KM, Beynnon BD. Early revision for component malrotation in total knee arthroplasty. Clin Orthop Relat Res 2007;458:131-136.

34. Incavo SJ, Coughlin KM, Pappas C, Beynnon BD. Anatomic rotational relationship of the proximal tibia, distal femur, and patella. J Arthroplasty 2003;18:643648.

35. Liu ZT, Fu PL, Wu HS, Zhu Y. Patellar reshaping versus resurfacing in total knee arthroplasty -results of a randomized prospective trial at a minimum of 7 years' follow-up. Knee. 2012 Jun;19(3):198-202.

\section{SUBMISSION HISTORY}

Submitted February 19, 2017

Reviewed June 1, 2017

Revised June 25, 2017

Accepted July 14, 2017

Published September 30, 2017

\section{AUTHOR AFFILIATIONS}

1 Justin M Head, D0; Ryan Nelson, D0; Mark Dyball, DO; Bruce D Lawrence, DO Genesys Regional Medical Center, a Michigan State University Statewide Campus, One Genesys Parkway, Grand Blanc, MI 48439

(Direct inquires to Justin M Head, justin.head8@gmail.com)

AUTHOR DISCLOSURES

The authors declare that there are no disclosures regarding the publication of this paper.

\section{COPYRIGHT \& OPEN ACCESS}

(C) 2017 Head, Nelson, Dyball, Lawrence. All rights reserved. Authors retain copyright and grant the journal right of first publication with the work. Reconstructive Review is an open access publication and follows the Creative Commons Attribution-NonCommercial CC BY-NC. This license allows anyone to download works, build upon the material, and share them with others for non-commercial purposes as long as they credit the senior author, Reconstructive Review, and the Joint Implant Surgery \& Research Foundation (JISRF). An example credit would be: "Courtesy of (senior author's name), Reconstructive Review, JISRF, Chagrin Falls, Ohio". 